\title{
Towards a Retrospective and Prospective Vision for Lantau Island in Hong Kong That Sustains Cultural and Social Values
}

\author{
Hee Sun (Sunny) Choi \\ Urban Environments Design, School of Design, Hong Kong Polytechnic University, Hong Kong, China \\ Email: hee_sun26@hotmail.com
}

How to cite this paper: Choi, H. S. (2021). Towards a Retrospective and Prospective Vision for Lantau Island in Hong Kong That Sustains Cultural and Social Values. Current Urban Studies, 9, 227-237. https://doi.org/10.4236/cus.2021.92015

Received: April 21, 2021

Accepted: June 4, 2021

Published: June 7, 2021

Copyright $\odot 2021$ by author(s) and Scientific Research Publishing Inc. This work is licensed under the Creative Commons Attribution International License (CC BY 4.0).

http://creativecommons.org/licenses/by/4.0/

\section{(c) (i) Open Access}

\begin{abstract}
A sustainable urban vision needs to reflect the distinctive qualities, characteristics and identities of each individual space and city, integrated with evolving social and cultural aspects. This vision is also an expression of the integrated values and perspectives the inhabitants of each city have for what should be responsible and sustained. This paper provides a project-based critical assessment and review focusing in particular on a development called Swire Leadership Centre (SLC) in Lantau, Hong Kong. Using the case project, this paper suggests sustainable design alternatives with the value of local resources and cultural identity.
\end{abstract}

\section{Keywords}

Environmental and Social Sustainability, Cultural Sustainability, Place Making, Lantau Island

\section{Introduction}

Sustainability is a key issue in urban transformation and development in the 21st century. This is reflected in two recent publications from the UN (2019): the "Sustainable Development Goals" from 2019 and the "2020 Biodiversity Strategic planning and global biodiversity framework". These include a multi-disciplinary debate on how to achieve responsible and sustainable development. Sustainability means more than the protection of the environment; it requires a long-term vision for catalyzing positive change leading to sustainability in both social and environmental contexts. As such, global movements and goal-setting need to reflect the distinctive nature and characteristics and identities of each city, integrated with the identity of the inhabitants and their social \& cultural values. 
Certain urban development models offer an environmentally sustainable vision but can have the effect of breaking the existing social and cultural structure, and through these relations between individuals also. To address this, solutions to environmental problems should also consider the maintenance and reconstruction of social and cultural issues, as well as with economic policies that take into account the natural capital as one of the biggest values for the future.

Considering this collective determination for achieving sustainability, this paper provides a spatial assessment based on a completed project: the Swire Leadership Centre (SLC) on Lantau Island in Hong Kong, as a test case that can suggest new possibilities to both designers and decision makers. The assessment is focused on how new environments can be designed to achieve both environmental and cultural sustainability in a way that provides a rooted yet future oriented link between the local environment and the local culture, not only in Hong Kong, but also in different cases and contexts.

Over the last 25 years, the UNFCCC and other international societies (FSD, IISD, ISDRS, ISBE) have proposed that governments worldwide should address the rising levels of air pollution and greenhouse gases produced within cities. Given the finite natural energy resources involved, these recommendations and proposals include special consideration for alternative approaches to the generation of energy within urban development.

The impact of climate changes brought about through rapid urban development and infrastructural growth in developing countries, including within the South East and East Asian region, has meant that these developing countries have started to respond to the need for alternative approaches to this development and growth. As is the case in densely populated areas worldwide, energy efficiency in buildings encompasses the most diverse, largest and most cost effective opportunity to tackle climate change in Hong Kong. The building sector is the biggest user of energy in the city, with most of the energy consumed by buildings after construction is completed. For example, recent statistics regarding Hong Kong (Electrical and Mechanical Services Department, 2020) show that consumption associated with the built environment is as follows:

- In 2018, the Residential Sector of Hong Kong consumed 61,439 TJ of energy with 43,120 TJ being electricity (GHG emission figures as published by Environmental Protection Department). The energy and electricity increased by $13.8 \%$ and $21.7 \%$ for the period 2006-2016 respectively (increased at an average annual rate of $1.3 \%$ and $2.0 \%$ respectively).

- In 2018, the Commercial Sector of Hong Kong consumed 123,969 TJ, around $83.8 \%$ or $103,881 \mathrm{TJ}$ of which was electricity. The energy and electricity increased by $10.8 \%$ and $11.3 \%$ for the period 2006-2016 respectively (increased at an average annual rate of $1 \%$ and $1.1 \%$ respectively).

At a strategic level, the "Sustainable Lantau Blueprint" from June 2017 is the most recent development proposal that attempts to address this question, by reconsidering the relationship between the natural habitats, sustainable wildlife 
and planning strategies for Lantau Island. In collaboration with the Lantau Development Advisory Committee (LanDAC) and taking into account a public engagement exercise carried out between January and April 2016, a Sustainable Lantau Blueprint guiding the future development and conservation for Lantau was formulated. Following the overarching planning vision during the formulation of the Concept Plan and Revised Concept Plan for Lantau in 2004 and 2007, the proposed planning and development framework for Lantau showing the overall strategy formulated under Hong Kong 2030+ below (Lantau Task Force the Concept Plan);

1) developing East Lantau Metropolis (ELM) as a strategic growth area (SGA):

- with a capacity of accommodating population of about 400,000 to 700,000 and creating employment of about 200,000;

- with the third Core Business District (CBD3) as a new and smart financial and producer services hub at a strategic location bridging Hong Kong Island and Lantau;

2) developing various economic nodes in northern Lantau as an important component of the Western Economic Corridor;

3) conserving the natural and cultural assets of Lantau as Hong Kong's treasure; and

4) forming a strategic transport corridor linking Northwest New Territories (NWNT)-Lantau-ELM-Metro Area to support the proposed ELM and the territorial development.

A key element of the blueprint is the construction of a new island, with the aim of social redistribution, population redistribution and spatial reorganization, whilst attracting global investment to support industrial growth at the local level and the forming of finance and economic power in Lantau to link Macau as well as Mainland China at the international level (Park \& Lee, 2004). The government led development is seeking to provide opportunities for strategic economic and housing development at the northern shore and conservation of natural and cultural resources with some sustainable tourism and recreation uses.

Reviewing the sustainable development plan, with supporting facilities for the community, the government proposed to provide sufficient education, health, leisure, recreation and community facilities and public open space as a holistic approach for achieving a liveable community. However currently (2020) no further detail on how this will be achieved has been published. In terms of neighbourhood and community development within a strategy of sustainable development in Lantau, the green pathway along the north park of Tung Chung and pedestrian promenade aligned with the waterfront provide a new walking environment which it is proposed will be developed into a town park connecting the west and the town centre of Tung Chung, as a means to facilitate a pedestrian friendly environment.

In terms of cultural sustainability, Lantau is one of the earliest settlements in Hong Kong and possesses a wealth of monuments, historic buildings and sites of 
archaeological interest. There are a number of significant activities and heritages of archaeological and cultural value to sustain, such as the renowned Po Lin Monastery in Ngong Ping and the Dragon Boat Water Parade in Tai O which is included in the list of China's national intangible elements (see Figure 1).

In addition, the Government is expediting land supply in a multi-pronged approach, e.g. re-zoning of under-utilised GIC sites and identification of possible cavern areas for relocation of government facilities and hence releasing land for residential, commercial or other uses.

Spontaneously, in terms of infrastructure, the Government has identified a number of Strategic Cavern Areas in Mui Wo and North Lantau (near Sham Shui Kok, Siu Ho Wan and the surrounding area of Tung Chung) under the Cavern Master Plan (see Figure 2), including sewerage, waste disposal systems and water supplies facilities, to release their original surface sites for more beneficial uses.

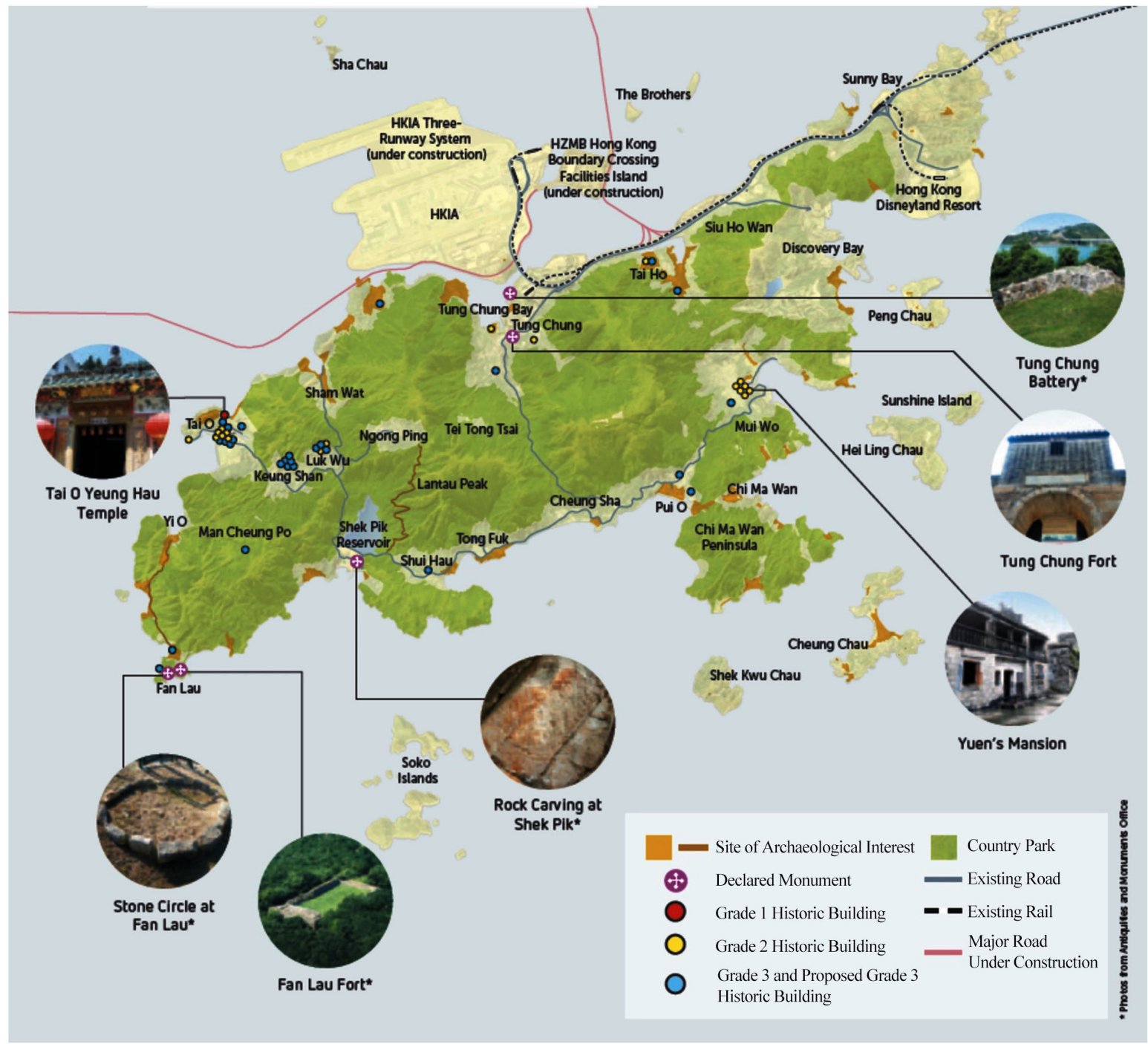

Figure 1. Major cultural heritage resources in Lantau (source: Hong Kong Development Bureau, 2017). 


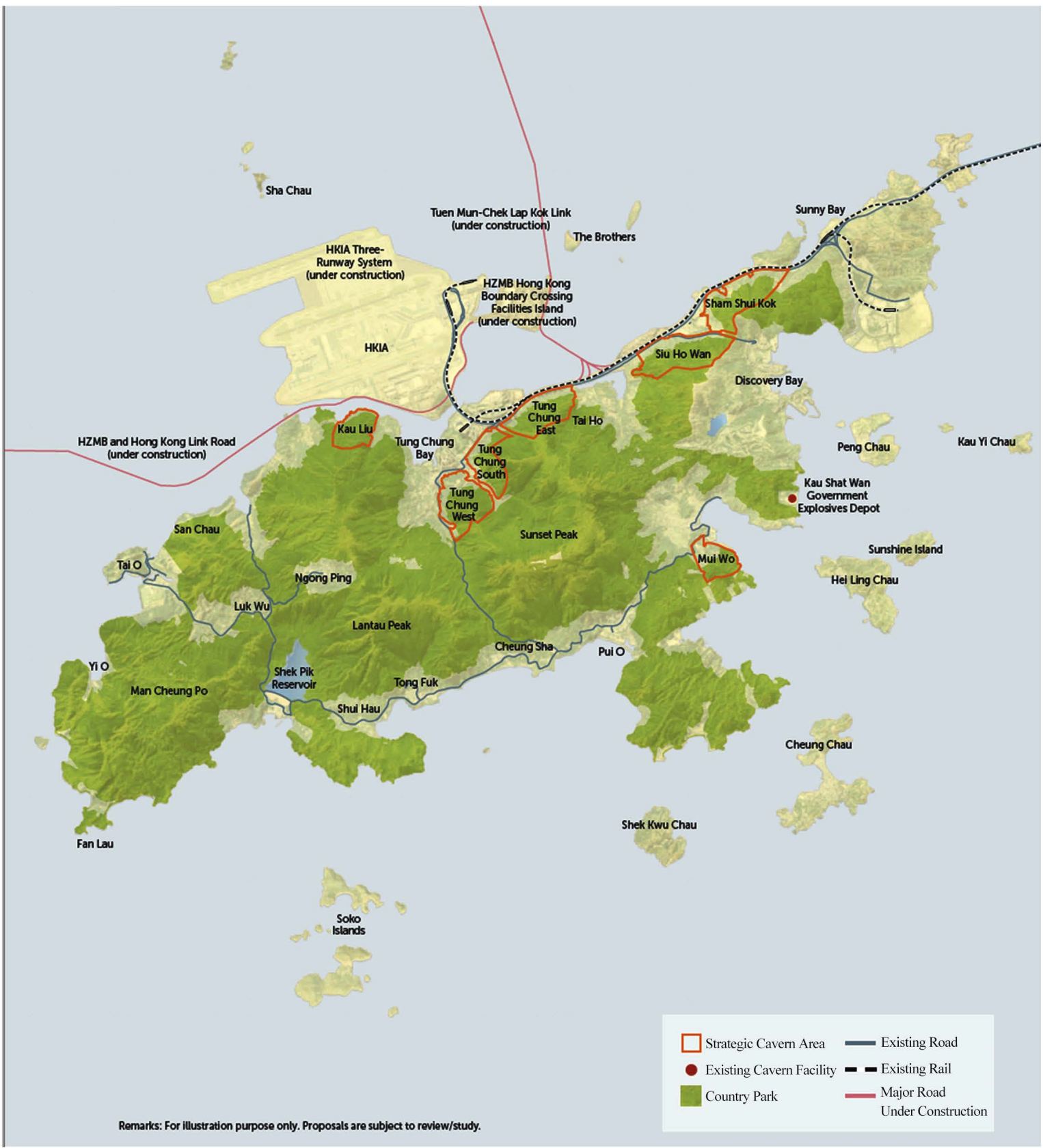

Figure 2. Strategic cavern areas in lantau (source: Hong Kong Development Bureau, 2017).

In terms of a spatial network to meet the transport needs arising from a sustainable Lantau development, the planning and implementation of a comprehensive traffic and transport infrastructure network is planned, not only comprising strategic railway and road systems in support of the proposed strategic developments in North Lantau but also water transport and transport facilities are considered in terms of enhancing internal connection and accessibility of Lantau.

Considering these planning and design strategies and objectives, it has been argued that the most important thing for such initiatives is that the built environment should be largely determined by the communities that dwell there and 
the buildings reflect the needs of the individuals and different key actors, physical and social structure, and the physical location of the structures (Bentley, 1999; Carmona, 2003; Lee, 2002).

The physical environment includes the heritage, buildings, natural resources, geography, metabolism, biodiversity. The social environment includes the lifestyles, ways of living, local knowledge, celebrations, traditions, symbols, myths and beliefs as a collective, subjective value for development, with cultural sustainability also providing the opportunity for indvidual expressions of creativity and diversity.

Understanding this, a deeper and holistic understanding of sustainable urban components is a challenge when assessing the merit of individual proposals. For instance, Mui Wo in Lantau has its tranquil and rural township character. Through re-planning and optimisation of existing under-utilised land together with the possible cavern development, Mui Wo could be revitalised as an enhanced township response to local character with small amount of low-density residential developments as well as balancing the needs of development/ improvement and preservation of Mui Wo's local resources and ecosystem with a view to retaining local heritage and cultural values.

This understands the exercise of sustainability and sustainable design as a recognition of the value of culture that characterizes both the social and physical environment-natural and built. For this reason, this understanding of sustainability not only involves recognizing how culture has shaped both the physical and social environment as a first principle of efficiency because it leverages the existing and learns from what has been learned, but also, and especially, ensures freedom of expression of any individual or group in any format. In other words, it understands that the new should not be built on nothing but contextualized in the cultural framework that houses it, not only recognizing the value of existing expressions of subjectivity but encouraging new collective and individual modes of expression.

In short, a culturally sustainable action encourages society to recognize and identify itself with it. Thus, a society that loves and respects both the human and social, and the natural and built environment in which it lives-because it recognizes itself with them-is a more prepared, conscious, informed, free society, caring, involved, etc. to take on other issues of sustainable development-"social inclusion, economic growth and environmental balance" (World Commission on Environment and Development, 1987).

\section{Critical Review of a Completed Project in Lantau}

One private development in South Lantau that seeks to strike that balance is the Swire Leadership Centre (SLC), a new training facility for the Swire group of companies that include Cathay Pacific, food production and distribution and property development. Swire first built a holiday park for their staff on the site in South Lantau (see Figure 3) in 1977 and the accommodation had become outdated 


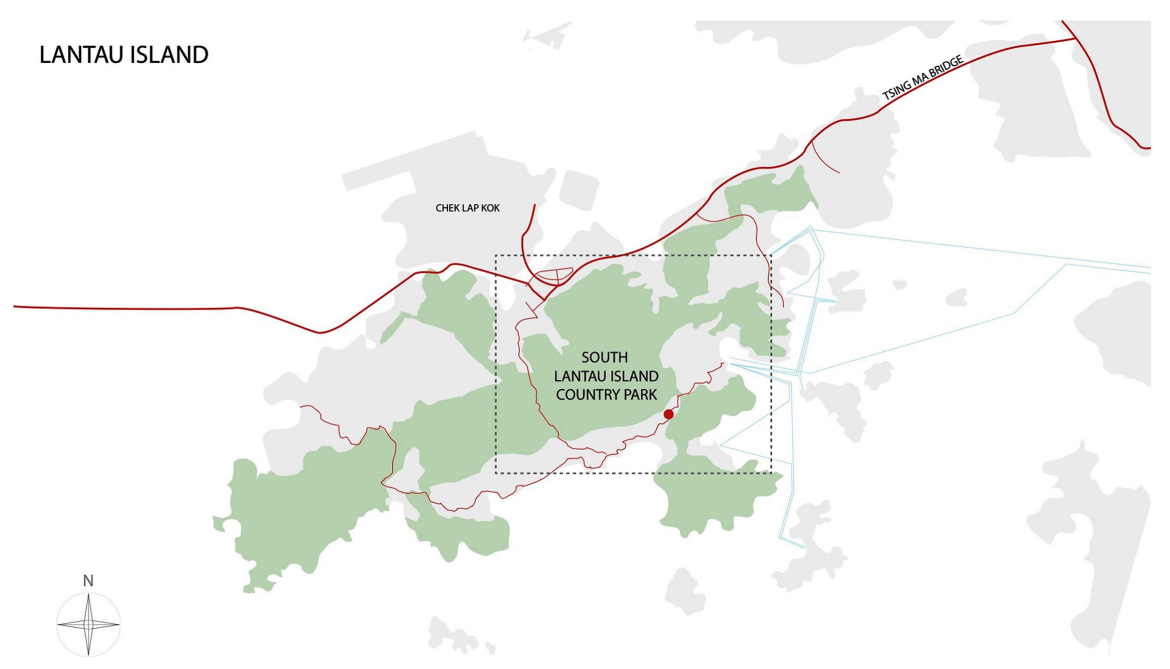

Figure 3. Swire leadership centre-location plan.

and lacked the arrangement and facilities for contemporary training methods. Completed over a four year period 2014-2018, with a consultant team including Make, LWK Architects, Choi-Comer Asia, Wong and Ouyang and landscape designer Urbis, the new centre replaced the old, including 28 residential rooms and four large training training rooms, arranged around a landscaped courtyard and with the integration of over 350 archive items from the client's company history.

From a planning and urban design perspective, the positioning and orientation of the new building, using memorable historical archive items within the landscape, gave consideration to the redevelopment of the wider Pui O and Mui Wo district along South Lantau Road as part of a culturally and environmentally sustaining and sustainable approach.

The SLC has an architectural design and landscaped gardens that references the setting and topography. Nestled within the hillside, the accommodation is arranged to look both outwards and inwards (see Figure 4).

The building achieved a LEED platinum rating through the usage of a sustainable material palette including natural timber and a mechanical fan in all guest rooms to reduce the reliance on air conditioning. Openable windows and doors at both sides of training and guest rooms further encourage natural ventilation, and a sedum roof covering provides a method of insulation that helps the building intergrate both visually and environmentally into its landscape setting and surrounding eco-system.

In relation to cultural identity, the Swire group have been an important and integral part of Lantau Island over the last 30 years, particularly in relation to their ownership and management of the Hong Kong airline Cathay Pacific and involvement in the Island's Chek Lap Kok Airport, freight terminal and Cathay City administration complex. This engagement in travel and shipping has been an integral part of the company history since its founding in 2016. 


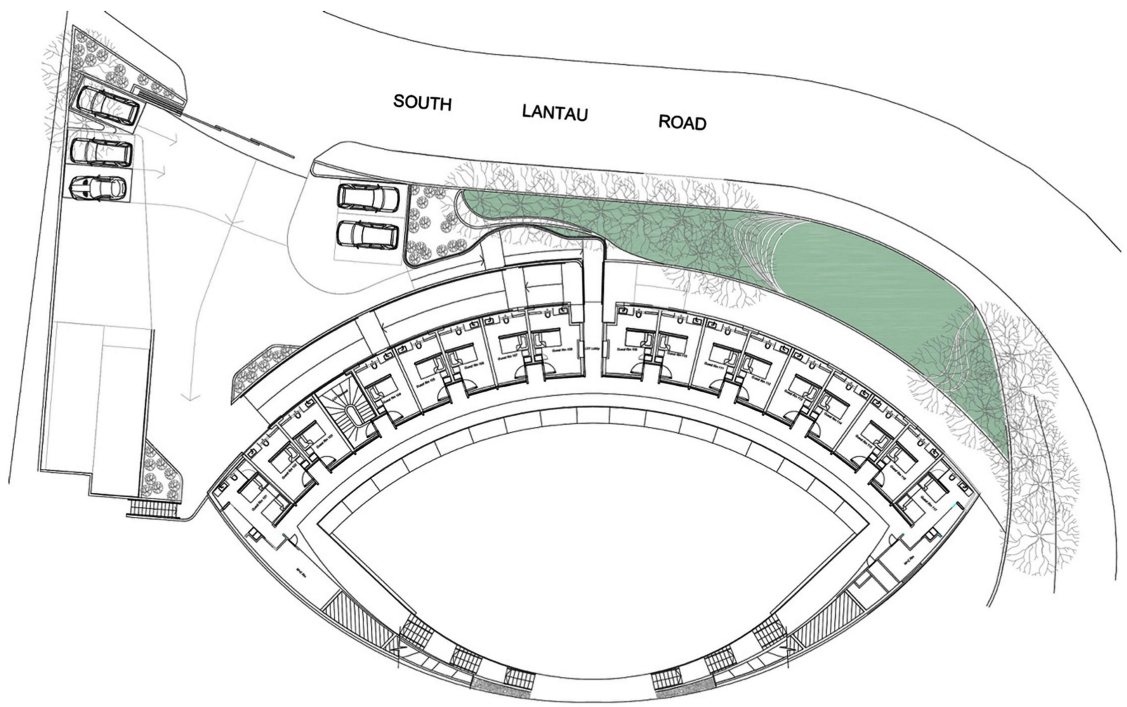

N)

FIRST FLOOR INDICATIVE PLAN

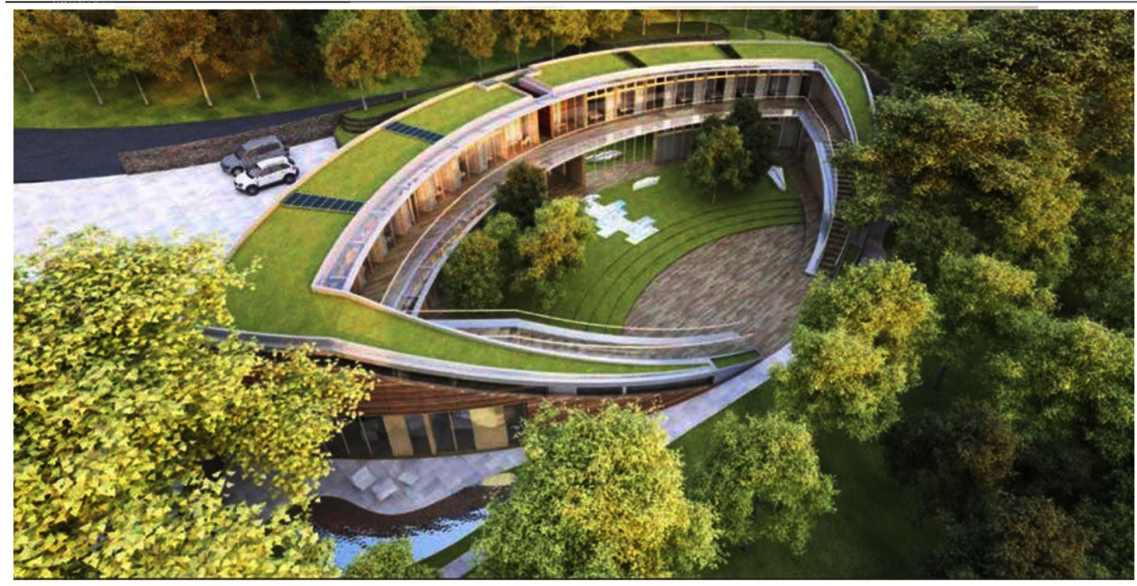

Figure 4. Swire leadership centre.

This history is illustrated in the archive of items that are placed within the common areas, access corridors and central gallery space of the Leadership Centre. The Swire motto "Esse Quam Videri", Chinese name 太古, and 200 years of the company history are all etched into the panelling and handrail of the building facade around the central courtyard.

The ground level interior includes three training rooms, an additional canteen-cum-mulitfunctional space, and central gallery space. All are connected with movable wall panels, so that the spaces can be opened up as one large space. The central gallery includes glazed partitions that allow for double sided exhibition of the some of the paper archive items, including two sided written letters from Swire staff from the early 1900s, that offer an interesting insight into expatriate life for the current staff on training, with sentences about homesickness and exotic foods perhaps striking a chord.

In the canteen a series of decorative fans from the Cathay Pacific are exhibited 
and provide inspiration for large folded metal panelling that runs around two walls. The canteen also includes exhibits from the company's food and beverage subsidiaries Coca Cola and Taikoo Sugar, and drinks coasters reproduced from the Cathay Pacific inflight dining (see Figure 5).
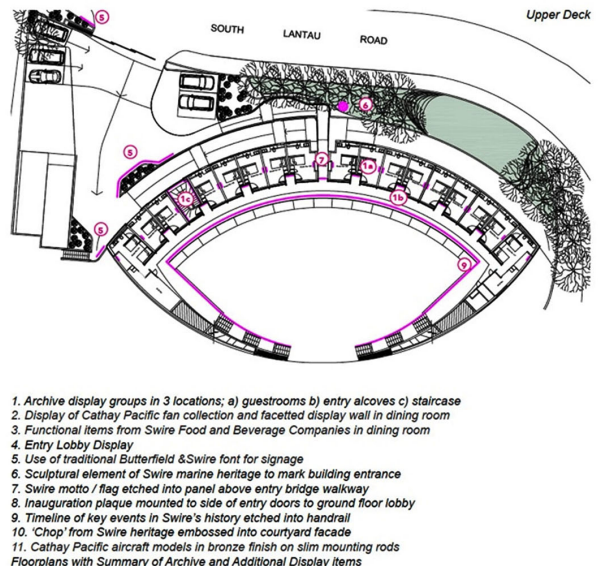
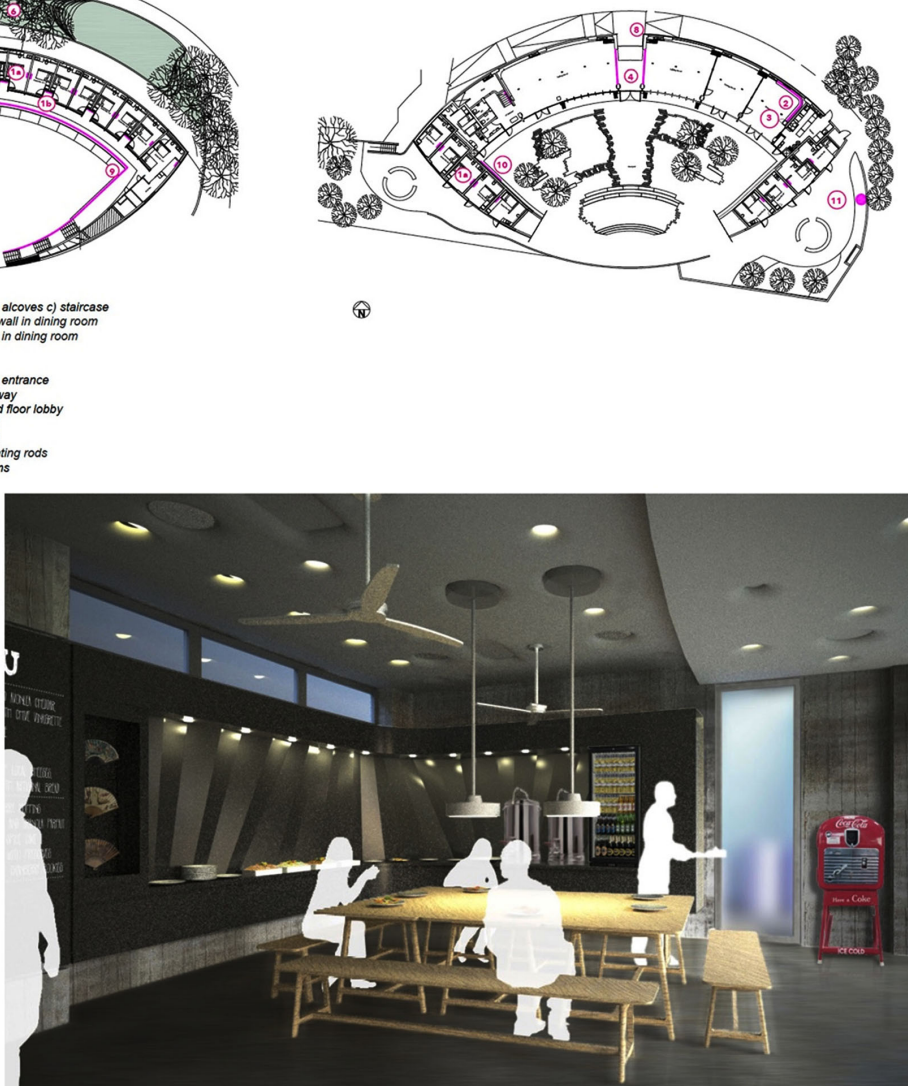

ITEMS 2 AND 3
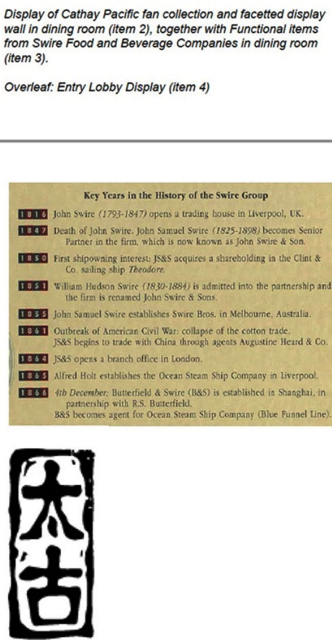
Timelline of key events in Swire's history etched into handral
(Item 9 , and traditional 'chop' 'rom Swire hertige embossed
into side panelling of courtyard facede (titem 10)

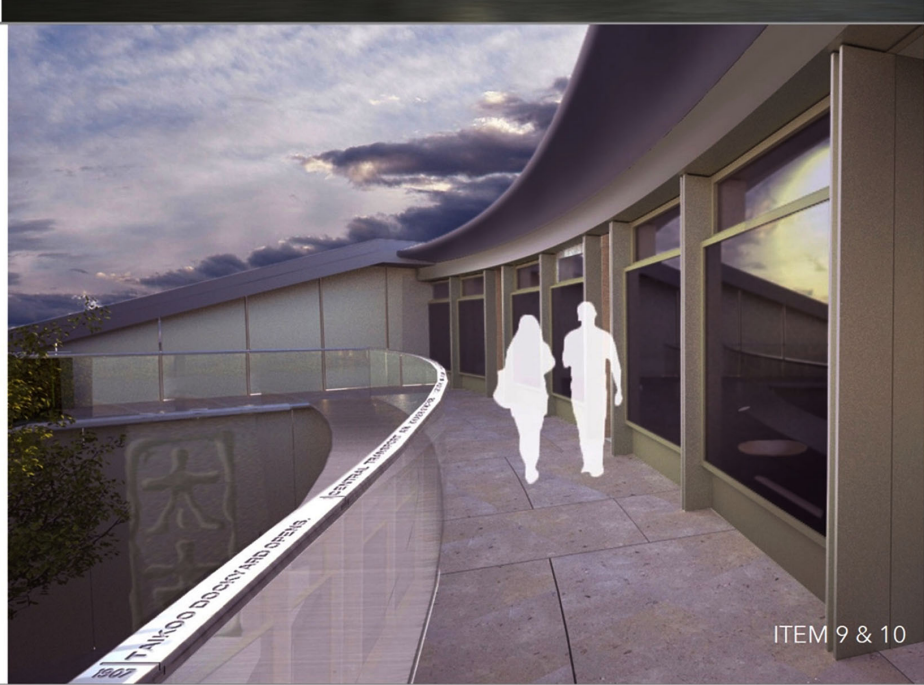

Figure 5. Swire Archive items and restoration with different forms. 
From the bigger scale at an urban level, access to this building is limited and for private use. Whilst the plan is open towards the sea, it is closed off to the street except for the gated carpark entry. The internal courtyard landscape design has maintained existing trees within the site together with a new landscape design with a sustainable species group suitable to the local habitat and ecosystem. The architectural design seeks to bed itself within the landscape setting, with a low-rise, curved form designed to provide an organic, relaxed setting.

Regarding the importance of social capital within development, Bourdieu (1992: p. 139) argued that "Social capital is an attribute of an individual in a social context. One can acquire social capital through purposeful action and can transform social capital into conventional economic gains. The ability to do so, however, depends on the nature of the social obligations, connections, and networks available to you." Dyllick and Hockerts (2002: p. 133) define two types of social capital: human capital and societal capital, where societal capital includes "the quality of public services, such as a good educational system, infrastructure or a culture supportive of entrepreneurship".

Knowing that, for a deeper sense of understanding and causal directions to be identified requires further attention to the complexities of these aspects' interlinkages, processes, and relations from the past to the future, and from sense of belonging, memorability to social and cultural value not only at a community level but also at a national level.

The notion of sustainability can be defined not as some fixed perfect state, but rather an evolving one that responds to both change in the form production processes as well as ecological change. Based on this understanding, this project provides an example of how the social and cultural identity of a newly designed built environment can marry with the concepts of sustainable urban development, in both planning and practice. In this way culture can be both an enabler and a driver of the economic, social and environmental dimensions of sustainable development.

\section{Final Conclusion}

In summary, this paper has attempted to offer some guidance towards design practice in the creation of sustainable place-making, whilst providing a basis for developing a strategy and process to achieve sustainable urban development. Also it can contribute to defining the importance of greater consideration for cultural and social capitals in sustainable development, via a shift in political and social ideology within the urban environment.

The case study for the Swire Leadership Centre offers at a small scale an example of how a development's cultural context can add value to place making and the identity of a local area.

This is only a small case study and so only offers a snapshot. Further research would be able to offer a review of a larger case study and case study group.

In summary, this paper has contributed to offering some guidance towards 
design practice in the creation of sustainable place-making, whilst providing a basis for developing a strategy and process to achieve sustainable urban development. Specifically, this paper contributes to defining the importance of greater consideration for cultural and social capitals in sustainable development, via a shift in political and social ideology within the urban environment.

In conclusion, the creation of a sustainable city does not only concern environmental considerations, it can also be rooted in a cultural life that, rather than fade away, can continue to be restored and evolved.

\section{Conflicts of Interest}

The author declares no conflicts of interest regarding the publication of this paper.

\section{References}

Bentley, I. (1999). Urban Transformation: Power, People and Urban Design. London: Routledge.

Bourdieu, P., \& Wacquant, L. J. D. (1992). An Invitation to Reflexive Sociology. Chicago, IL: Chicago University Press.

Carmona, M. (2003). Public Places-Urban Spaces: The Dimension of Urban Design. Oxford, UK: Architectural Press.

Dyllick, T., \& Hockerts, K. (2002). Beyond the Business Case for Corporate Sustainability. Business Strategy and the Environment, 11, 130-141. https://doi.org/10.1002/bse.323

Electrical and Mechanical Service Department (2020). Energy End-Sue Data and Consumption Indicator: Hong Kong Energy End-Use Data. Government of the Hong Kong Special Administrative Region.

https://www.emsd.gov.hk/en/energy_efficiency/energy_end_use_data_and_consumpti on_indicators/hong_kong_energy_end_use_data/

Hong Kong Development Bureau (2017). Sustainable Lantau Blueprint. https://www.lantau.gov.hk/en/home/index.html

Lee, H. S. (2002). The Concept of Le Corbusier's Architecture and Urban Planning. Seoul, South Korea: TaeLim Press.

Park, D., \& Lee, J. (2004). Global Innovation Clusters. Seoul: Hanul Academy.

UN (2019). Sustainable Development Goals.

https://www.un.org/sustainabledevelopment/sustainable-development-goals/

World Commission on Environment and Development (WCED) (1987). Brundtland Report.

https://sustainabledevelopment.un.org/content/documents/5987our-common-future.p df 